Research Article

\title{
Clinical and Radiographic Characteristics as Predictive Factors of Swelling and Trismus after Mandibular Third Molar Surgery: A Longitudinal Approach
}

\author{
José Manuel Pérez-González, ${ }^{1}$ Vicente Esparza-Villalpando, ${ }^{2}$ Ricardo Martínez-Rider, ${ }^{1}$ \\ Miguel Ángel Noyola-Frías, ${ }^{1}$ and Amaury Pozos-Guillén $\mathbb{1}^{3}$ \\ ${ }^{1}$ Department of Oral and Maxillofacial Surgery, Faculty of Dentistry, San Luis Potosi University, San Luis Potosí, SLP, Mexico \\ ${ }^{2}$ Engineering and Materials Science Postgraduate Program, San Luis Potosi University, San Luis Potosí, SLP, Mexico \\ ${ }^{3}$ Basic Sciences Laboratory, Faculty of Dentistry, San Luis Potosi University, San Luis Potosí, SLP, Mexico
}

Correspondence should be addressed to Amaury Pozos-Guillén; apozos@uaslp.mx

Received 15 February 2018; Revised 22 March 2018; Accepted 5 April 2018; Published 23 April 2018

Academic Editor: Eugenio Velasco-Ortega

Copyright (C) 2018 José Manuel Pérez-González et al. This is an open access article distributed under the Creative Commons Attribution License, which permits unrestricted use, distribution, and reproduction in any medium, provided the original work is properly cited.

\begin{abstract}
Introduction. Factors that contribute to swelling and trismus are complex, and they are originated by surgical trauma. The aim of the present study was to determine whether clinical and radiographic factors could predict the level of swelling and trismus after lower third molar surgery, through longitudinal approach. Methodology. A prospective longitudinal trial was carried out. Fortyfive patients of both genders with clinical and radiographic diagnosis of asymptomatic mandibular impacted third molar and with no intake of analgesic or anti-inflammatory drugs $12 \mathrm{~h}$ prior to surgery were recruited and evaluated in a $72 \mathrm{~h}$ follow-up period. A mixed repeated measures model and backward and restricted maximal likelihood methods were used to analyze the data. Results. Male gender, body mass index (BMI), the relation to the lingual and buccal walls, and age were determinants for predicting postoperative swelling and for exerting a significant influence $(P<0.05)$. Conclusions. This study suggests the association of male gender, the relation to lingual and buccal walls, BMI, and age with measurement of swelling.
\end{abstract}

\section{Introduction}

Surgical extraction of mandibular third molars under local anesthesia involves the traumatic manipulation of bone, connective, and muscle tissues. Swelling, pain, and trismus are the principal postoperative signs and symptoms, which are caused mainly by tissue damage [1]. The effect of mandibular third molar surgery on the postoperative period in the majority of patients is marked by pain, swelling, and trismus, either alone or in combination [2]. Control of these conditions comprises an important factor for clinicians, because lower third molar surgery is one of the most common procedures carried out by oral and maxillofacial surgeons [3-7].

Factors that contribute to swelling and trismus are complex, and they are originated by surgical trauma $[8,9]$.
The control of swelling, pain, and trismus would be based on the understanding of the associated preoperative factors involved on the postoperative results. Previous reports of preoperative conditions related with swelling, pain, and trismus have included clinical and radiological factors [10], the difficulty of the procedure $[11,12]$, intraoperative factors $[13,14]$, and patients' characteristics [15]. These studies used a correlation between the different factors and the outcomes; the difficulty of this approach is that the clinical outcomes are dynamic and they change as a function of time. In transversal or punctual measurements, it is not possible to observe changes over time.

Considering a longitudinal approach, the aim of the present pilot study was to determine whether clinical and radiographic factors could predict the level of swelling and trismus after lower third molar surgery. 


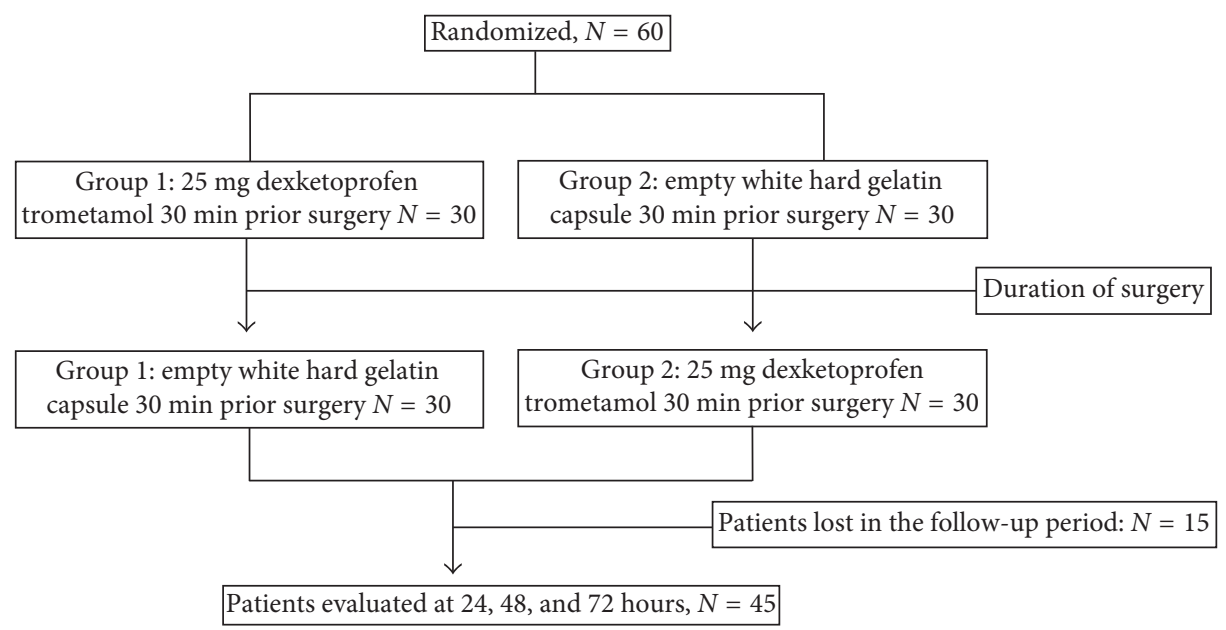

Figure 1: Flow chart of patient's distribution.

\section{Materials and Methods}

As part of previous study [4], the present prospective, longitudinal trial recruited 45 patients between 18 and 30 years old from the Department of Oral and Maxillofacial Surgery of the Faculty of Dentistry who had completed the 72-hour follow-up period. Briefly, the patients were assigned to two experimental groups. The first group received $25 \mathrm{mg}$ of dexketoprofen trometamol $30 \mathrm{~min}$ before surgery and 1 placebo capsule immediately after the surgery. The second group received the placebo capsule $30 \mathrm{~min}$ before surgery and $25 \mathrm{mg}$ of dexketoprofen trometamol immediately after the surgery. The local anesthesia was achieved by inferior alveolar nerve and lingual nerve blockade using lidocaine $2 \%$ with epinephrine 1:100,000 $\mathrm{mL}$ (FD ZEYCO, México), to remove one asymptomatic mandibular third molar. All the surgeries required mucoperiostical flap and osteotomy and were performed by the same surgeon. The patient distribution diagram is shown in Figure 1. The study was conducted in accordance with the Declaration of Helsinki, and the Institutional Ethics Committee approved the study design (CEI-FE-028-014). All participants were informed of the risks of oral surgery, and they signed a consent form.

Inclusion criteria were as follows: patients from both genders, with clinical and radiographic diagnosis of asymptomatic mandibular impacted third molar, and with no intake of analgesic or anti-inflammatory drugs $12 \mathrm{~h}$ prior to surgery. Exclusion criteria were the following: pregnant or breastfeeding patients, with the presence of systemic diseases such as diabetes, uncontrolled hypertension, or gastric ulcer, and patients with suspicion or evidence of narcotic or illicit drug use. Elimination criteria were all patients lost in the follow-up period (72 hours).

The facial points pogonion (Pg), labial commissure (Co), gonion (Go), outer eye corner (C), and tragus (T) were marked with indelible ink; measurements of swelling were performed with a millimetric ruler from the facial planes (T-Co, T-Po, C-Go, and Go-Co). The inflammation variable comprised the sum of all of the planes described previously (Figure 2). An independent examiner performed the measurements at the following different times: baseline/time 0

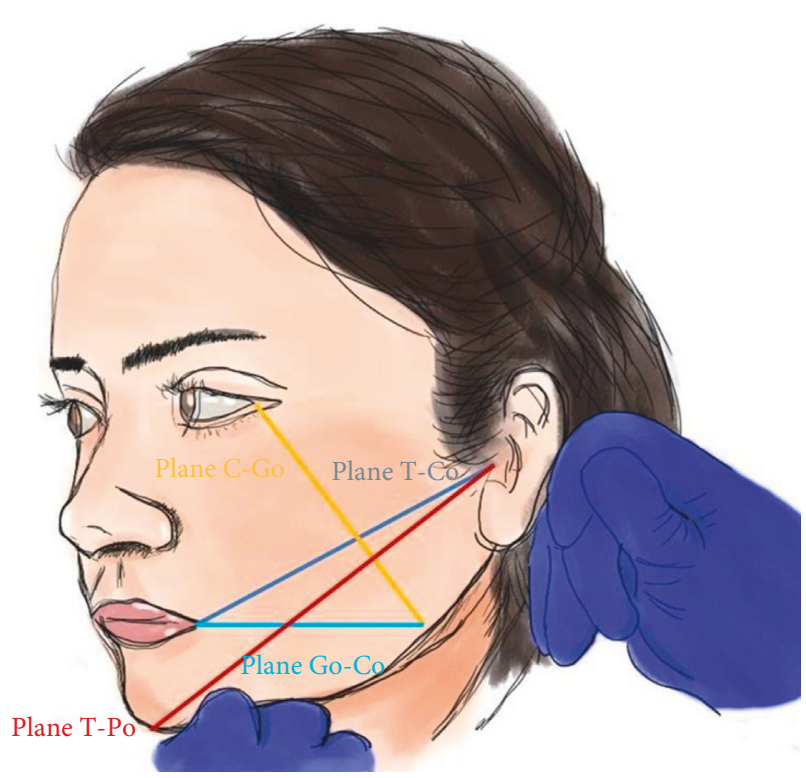

FIGURE 2: Facial planes for swelling measures.

(prior to the surgery); time 24 ( $24 \mathrm{~h}$ after the surgery); time 48 ( $48 \mathrm{~h}$ after the surgery), and time 72 ( $72 \mathrm{~h}$ after the surgery).

Trismus was measured with a millimetric ruler, asking the patient for the maximal oral opening possible and recording the distance from the incisal edge of the upper central incisors to the incisal edge of the lower central incisors. Clinical and radiographic variables recorded prior to the surgery are described in Table 1.

All patients were evaluated at 24, 48, and 72 postoperative hours. For swelling response as a dynamic process, a Mixed Repeated Measures Model (MRMM) analysis was employed. This model included all measurement times (random component), together with different variables (fixed component) (Table 1), and determined which variables result with significance in the swelling and trismus processes during the $72 \mathrm{~h}$ follow-up. Statistical software R ver. 3.2.3 was used, with the following packages: BBconRR, 
TABle 1: Variables included in the model (fixed component).

\begin{tabular}{|c|c|c|}
\hline Code & Variable & Units \\
\hline Gender & Gender of the patient & $\begin{array}{l}\mathrm{F} \text { (female) } \\
\mathrm{M} \text { (male) }\end{array}$ \\
\hline Baseline & Basal value (time 0 ) & $\mathrm{mm}$ \\
\hline Age & Age of the patient & Years \\
\hline BMI & Body mass index & $\mathrm{kg} / \mathrm{m}^{2}$ \\
\hline TQX & Surgical elapsed time & Minutes \\
\hline Total intake & $\begin{array}{c}\text { Total consumption of analgesic } \\
\text { intake in } 72 \text { hours }\end{array}$ & Number of tablets \\
\hline $\mathrm{R} 2 \mathrm{M}$ & $\begin{array}{l}\text { Relationship of the third molar to } \\
\text { second molar }\end{array}$ & $\begin{array}{l}\text { 0: Crown directed at or above the equator second molar } \\
\text { 1: Crown directed below the equator second molar } \\
\text { 2: Crown/roots directed to the middle of the second molar } \\
\text { 3: Crown/roots directed to the apical third of the second molar }\end{array}$ \\
\hline $\mathrm{RRM}$ & Relation to the mandibular ramus & $\begin{array}{l}\text { 0: Sufficient space in the dental arch } \\
\text { 1: Partially impacted in the ramus } \\
\text { 2: Completely impacted in the ramus } \\
\text { 3: Completely impacted in the ramus in distoangular position }\end{array}$ \\
\hline RRA & $\begin{array}{l}\text { Relation to the adjacent alveolar } \\
\text { crest (from the uppermost point of } \\
\text { the tooth) }\end{array}$ & $\begin{array}{l}\text { 0: Completely erupted } \\
\text { 1: Partially impacted, but widest part of the crown (equator) is above the bone } \\
\text { 2: Partially impacted, but widest part of the crown (equator) is below the bone } \\
\text { 3: Completely impacted } \\
\text { 0: Closer to buccal wall }\end{array}$ \\
\hline RRB & $\begin{array}{l}\text { Relation to the lingual and buccal } \\
\text { walls }\end{array}$ & $\begin{array}{l}\text { 1: In the middle between lingual and buccal walls } \\
\text { 2: Closer to lingual wall } \\
\text { 3: Closer to lingual wall, when the tooth is partially/completely impacted }\end{array}$ \\
\hline
\end{tabular}

car, ggplot2, nlme, reshape, and Rcmdr, with 95\% confidence intervals (95\% CI).

\section{Results}

Forty-five patients were analyzed during a $72 \mathrm{~h}$ follow-up period. The baseline characteristics of the sample are described in Table 2.

For the swelling and trismus variables, the multivariate MRMM, restricted maximal likelihood (REML), and backward-stepwise methods were used. The initial model included all of the variables in the fixed component described in Table 1, and, in the random component, all times were included and each patient was measured 3 times, for a total of 135 measurements. For the swelling model, we used a "varIdent" variance structure [16]; this model was compared with the null model (only intercept included) and this comparison showed $p$ value $<0.05$. Therefore, and based on the likelihood test, we determined the maximal parsimony model and deleted no significant terms in each iteration; the final model included the significative variables $(p<0.05)$ : GENDER, AGE, BMI, and $\mathrm{RRB}$, and the estimates and the significant values are shown in Table 3.

For the trismus variable in the MRMM, the same previous methods were used, and the variance structure utilized was "varPower" [16]; the fixed component included all variables presented in Table 1 , and the random component included all trismus measures. The model was compared with the null model (only intercept included), and this comparison showed $p$ value $>0.05$. Thus, the variables included in
TABle 2: Basal characteristics.

\begin{tabular}{|c|c|c|}
\hline Variable & $n=45$ & Min-max \\
\hline Age (mean (sd)) & $23.58(3.34)$ & $18-29$ \\
\hline Gender $=$ male $(\%)$ & $11(24.4)$ & - \\
\hline BMI (mean (sd)) & $23.90(3.24)$ & $18.87-32$ \\
\hline TQX (mean (sd)) & $19.02(5.38)$ & $7-28$ \\
\hline Total intake (mean $(\mathrm{sd}))$ & $4.8(2.61)$ & $0-9$ \\
\hline \multicolumn{3}{|l|}{ R2M (\%) } \\
\hline 0 & & \\
\hline 1 & & \\
\hline 2 & & \\
\hline \multicolumn{3}{|l|}{ RRM (\%) } \\
\hline 0 & & \\
\hline 1 & & \\
\hline 2 & & \\
\hline \multicolumn{3}{|l|}{ RRA (\%) } \\
\hline 1 & & \\
\hline 2 & & \\
\hline 3 & & \\
\hline \multicolumn{3}{|l|}{ RRB (\%) } \\
\hline 0 & & \\
\hline 1 & & \\
\hline 2 & & \\
\hline
\end{tabular}

TABLE 3: Estimates of the significant variables for swelling response.

\begin{tabular}{|c|c|c|c|c|}
\hline Variable & Slope value & CI 95\% & $P$ value & Etâ2 \\
\hline Gender (male) & 40.99 & $28.6,53.4$ & $<0.000001$ & 0.2613 \\
\hline BMI & 3.06 & $1.4,4.8$ & 0.00027 & 0.0841 \\
\hline RRB & $\begin{array}{ll}R B 1 & 38.82 \\
R B 2 & 44.74\end{array}$ & $\begin{array}{c}14.8,62.8 \\
19.7,69.7\end{array}$ & 0.00143 & 0.0646 \\
\hline Age & -2.57 & $-2.6,-1.0$ & 0.00068 & 0.0591 \\
\hline Residual & - & - & - & 0.5309 \\
\hline
\end{tabular}


the fixed component do not explain the changes in the trismus measures.

\section{Discussion}

To understand clinical and radiographic characteristics as predictor factors of swelling and trismus, after mandibular third molar surgery, it is important to recognize the risk factors associated with clinical complications. Several studies have measured the difficulty of this surgical procedure and clinical and radiological factors $[1,11-14,17,18]$.

Swelling has been determined by different techniques described in the literature; these techniques include visual inspection [6], facial points [19], photographic techniques [20], Computed Tomography (CT) [21], and others [7, 15, 22]. In the present study, swelling was estimated by the sum of the four facial planes. The advantages of this method are its simple implementation and low cost. Trismus was determined by maximal opening of the mouth and the distance between the lower and upper incisors.

Gender, body mass index (BMI), relation to lingual and buccal walls, and age of the patients were determinants in explaining the swelling measurements. The importance of gender in facial swelling was found in the present study, swelling was higher in males than in females, this agreement with that reported by Yuasa and Sigiura [15]. These authors, with a total of 140 patients (153 surgical procedures, 64.7\% females), used a sum of two planes (T-Co and C-Go) divided by 2 , to measure facial swelling. Measurements were made on postoperative days 1 and 7 . The statistical analyses used in their study included logistic regression and correlation without multiple measurements, and the difference between both sexes in the swelling was observed in the first time. This cannot be extended to the dynamic process of swelling. To deal with this issue, we propose the analysis of variables with the MRMM, which is applicable with the longitudinal design in our study [23].

On the other hand, de Santana-Santos et al. [24] reported the influence of the "gender" of the patients in the prediction of swelling. These authors found higher swelling in females than in males, with a sample size of 80 patients (32.5\%, females). They employed five measurements of distance between two facial points (the sum of five measurements divided by 5); the measurements were made on postoperative days 2 and 7 , and the statistical analysis used was correlation and group differences in one measurement time. Osunde and Saheeb [25] did not find a significant effect of sex on the swelling variable; these authors recruited a total of 150 patients ( $56 \%$, female). They used the arithmetic mean of two planes (T-Co and C-Go) and the difference between each postoperative measurement at days 1,2, 3, 5, and 7 and baseline as swelling measurement of the day. However, the authors found a higher mean facial swelling in females than in males, but this result was not significative. The analysis used in their study was one-way ANOVA.

BMI was also reported by de Santana-Santos et al. [24]; they did not find an association with the prediction of swelling. In their study, the authors categorized the BMI value and the swelling measurement. BMI is a measurement of body fat based on height and weight; adipose tissue is a major contributing factor to systemic inflammation, generating approximately one third of the circulating proinflammatory cytokine InterLeukin (IL)-6 [26]. The association of BMI and swelling has been previously explained; people with obesity often experience higher concentrations of inflammatory biomarkers than their normal-weight counterparts $[26,27]$. In the present study, the BMI variable had a low weight to explain the swelling in the patients (Table 3).

The relation of lower third molar with lingual and buccal walls has not been, to our knowledge, reported previously as a predictor factor of swelling. Several studies have reported the radiographic classification as a factor contributing to the complexity of the surgery $[6,13,17,28,29]$. In the present study, the proximal relation of the lower third molar to the lingual wall, or the relation in the middle position between buccal and lingual walls, corresponded to an increase in the swelling measures in the postoperative evaluation; this can be explained by the hard tissue removed. When the third molar is buccally erupted, the total bone removed for the surgical extraction is lower; on the other hand, when the third molar is in lingual position, the amount of bone removed increases.

The age of the patients has been reported as a predictive factor for swelling. Olmedo Gaya et al. [30] reported increased swelling with increased age. According to a report by Bello et al. [29], there is a positive association between age and swelling and age and trismus. Finally, Osunde et al. [12] did not show a significant association between age and swelling in mandibular third molar surgery. In the present study, the age variable shows an inverse relationship with swelling; this implies that if the patient's age increases, the swelling decreases; however, this relationship shows low weight to explain the swelling (Table 3). This relationship can be explained by the changes involved in the immune system associated with the inflammatory response related to age [31].

One of the advantages of this study is the multiple measurement period. Because the swelling process is dynamic and the main changes are present in the first $72 \mathrm{~h}$ [9], the MRMM can be adjusted for multiple measurements and used in a longitudinal approach, and the methods control the intra- and interpatient variability when repeated measures design is used and have a more flexible structure for the analysis $[23,32]$. The repeated measures design increased the number of measurements on the same patient; this means we can use more repetitions or measurement values in the model with the same number of patients. However, this type of analysis includes some limitations: the slope values are only valid in the range of the variables included; out of this range, this model cannot be applied. Moreover, the swelling measure was linear and not volumetric and did not involve the volume of the change of tissue. van der Meer et al. [22] and Yamamoto et al. [21] propose new methods to measure facial swelling, and the use of stereophotogrammetry, CT, and laser surface scanning comprises the principal elements in these procedures. The advantages of this include the reproducibility of the measures, in terms of volume and precision; however, cost and implementation must be taken into account in the planning of the clinical trials. 
Further studies are necessary to confirm these findings, with a higher sample size and variable ranges. We suggest the use of MRMM to analyze the data with a longitudinal approach and control the follow-up measurements during the first 72 hours. The facial planes method to measure the swelling can be useful; however, this method has some limitations, and other alternatives can be validated to this endpoint.

\section{Conclusions}

This study suggests the association of male gender, the relation to the lingual and buccal walls, BMI, and age with the swelling measurement. The trismus variable did not show any relationship with explanatory variables.

\section{Consent}

Informed consent was obtained from all individual participants included in the study.

\section{Conflicts of Interest}

The authors declare that they have no conflicts of interest.

\section{Acknowledgments}

This work was supported partially by PFCE-UASLP 2017 and PRODEP 2018 grants.

\section{References}

[1] R. D. Marciani, "Third molar removal: an overview of indications, imaging, evaluation, and assessment of risk," Oral and Maxillofacial Surgery Clinics of North America, vol. 19, no. 1, pp. 1-13, 2007.

[2] M. Colorado-Bonnin, E. Valmaseda-Castellón, L. BeriniAytés, and C. Gay-Escoda, "Quality of life following lower third molar removal," International Journal of Oral and Maxillofacial Surgery, vol. 35, no. 4, pp. 343-347, 2006.

[3] J. Perez-Urizar, R. Martinez-Rider, I. Torres-Roque, A. Garrocho-Rangel, and A. Pozos-Guillen, "Analgesic efficacy of lysine clonixinate plus tramadol versus tramadol in multiple doses following impacted third molar surgery," International Journal of Oral and Maxillofacial Surgery, vol. 43, no. 3, pp. 348-354, 2014.

[4] V. Esparza-Villalpando, D. Chavarria-Bolaños, A. GordilloMoscoso et al., "Comparison of the analgesic efficacy of preoperative/postoperative oral dexketoprofen trometamol in third molar surgery: a randomized clinical trial," Journal of Cranio-Maxillo-Facial Surgery, vol. 44, no. 9, pp. 13501355, 2016.

[5] M. Isiordia, A. Pozos-Guillén, R. Martinez, J. Herrera, and J. Perez, "Preemptive analgesic effectiveness of oral ketorolac plus local tramadol after impacted mandibular third molar surgery," Medicina Oral Patología Oral y Cirugia Bucal, vol. 16, no. 6, pp. 776-780, 2011.

[6] E. D. Amarillas-Escobar, J. M. Toranzo-Fernández, R. MartínezRider et al., "Use of therapeutic laser after surgical removal of impacted lower third molars," Journal of Oral and Maxillofacial Surgery, vol. 68, no. 2, pp. 319-324, 2010.

[7] M. Rana, N. C. Gellrich, A. Ghassemi, M. Gerressen, D. Riediger, and A. Modabber, "Three-dimensional evaluation of postoperative swelling after third molar surgery using 2 different cooling therapy methods: a randomized observer-blind prospective study," Journal of Oral and Maxillofacial Surgery, vol. 69, no. 8, pp. 2092-2098, 2011.

[8] T. Velnar, T. Baileym, and V. Smrkolj, "The wound healing process: an overview of the cellular and molecular mechanisms," Journal of International Medical Research, vol. 37, no. 5, pp. 1528-1542, 2009.

[9] R. A. Seymour, J. G. Meechan, and G. S. Blair, "An investigation into post-operative pain after third molar surgery under local analgesia," British Journal of Oral and Maxillofacial Surgery, vol. 23, no. 6, pp. 410-418, 1985.

[10] G. Juodzbalys and P. Daugela, "Mandibular third molar impaction: review of literature and a proposal of a classification," Journal of Oral and Maxillofacial Research, vol. 4, no. 2, pp. 1-11, 2013.

[11] F. Blondeau and N. G. Daniel, "Extraction of impacted mandibular third molars: postoperative complications and their risk factors," Journal-Canadian Dental Association, vol. 73, no. 4, p. 325, 2007.

[12] O. Osunde, B. Saheeb, and G. Bassey, "Indications and risk factors for complications of lower third molar surgery in a Nigerian teaching hospital," Annals of Medical and Health Sciences Research, vol. 4, no. 6, pp. 938-942, 2014.

[13] N. L. Barbosa-Rebellato, A. C. Thomé, C. Costa-Maciel, J. Oliveira, and R. Scariot, "Factors associated with complications of removal of third molars: a transversal study," Medicina Oral Patología Oral y Cirugia Bucal, vol. 16, no. 3, pp. 376-380, 2011.

[14] M. A. Pogrel, "What is the effect of timing of removal on the incidence and severity of complications?," Journal of Oral and Maxillofacial Surgery, vol. 70, no. 9, pp. 37-40, 2012.

[15] H. Yuasa and M. Sugiura, "Clinical postoperative findings after removal of impacted mandibular third molars: Prediction of postoperative facial swelling and pain based on preoperative variables," British Journal of Oral and Maxillofacial Surgery, vol. 42, no. 3, pp. 209-214, 2004.

[16] J. C. Pinheiro and D. M. Bates, "Approximations to the loglikelihood function in the nonlinear mixed-effects model," Journal of Computational and Graphical Statistics, vol. 4, pp. 12-35, 1995.

[17] J. Alvira-Gonzalez, R. Figueiredo, E. Valmaseda-Castellon, C. Quesada-Gomez, and C. Gay-Escoda, "Predictive factors of difficulty in lower third molar extraction: A prospective cohort study," Medicina Oral Patología Oral y Cirugia Bucal, vol. 22, no. 1, pp. e108-e114, 2017.

[18] P. Coulthard, E. Bailey, M. Esposito, S. Furness, T. F. Renton, and H. V. Worthington, "Surgical techniques for the removal of mandibular wisdom teeth," Cochrane Database of Systematic Reviews, vol. 7, p. CD004345, 2014.

[19] C. Gay-Escoda, L. Gómez-Santos, A. Sánchez-Torres, and J. M. Herráez-Vilas, "Effect of the suture technique on postoperative pain, swelling and trismus after removal of lower third molars: A randomized clinical trial," Medicina Oral Patología Oral y Cirugia Bucal, vol. 20, no. 3, pp. e372-e377, 2015.

[20] A. V. Van Gool, J. J. Ten Bosch, and G. Boering, "A photographic method of assessing swelling following third molar removal," International Journal of Oral Surgery, vol. 4, pp. 121-129, 1975.

[21] S. Yamamoto, H. Miyachi, H. Fujii, S. Ochiai, S. Watanabe, and K. Shimozato, "Intuitive facial imaging method for evaluation of postoperative swelling: A combination of 3-dimensional computed tomography and laser surface 
scanning in orthognathic surgery," Journal of Oral and Maxillofacial Surgery, vol. 74, no. 12, pp. 2506.e1-2506.e10, 2016.

[22] M. J. van der Meer, P. U. Dijkstra, A. Visser, A. Vissink, and Y. Ren, "Reliability and validity of measurements of facial swelling with a stereophotogrammetry optical three-dimensional scanner," British Journal of Oral and Maxillofacial Surgery, vol. 52, no. 10, pp. 922-927, 2014.

[23] M. Detry and Y. Ma, "Analyzing repeated measurements using mixed models," Journal of the American Medical Association, vol. 315, no. 4, pp. 407-408, 2016.

[24] T. de Santana-Santos, J. de Souza-Santos, P. Martins-Filho, L. da Silva, E. de Oliveira e Silva, and A. Gomes, "Prediction of postoperative facial swelling, pain and trismus following third molar surgery based on preoperative variables," Medicina Oral Patología Oral y Cirugia Bucal, vol. 18, no. 1, pp. e65-e70, 2013.

[25] O. D. Osunde and B. D. Saheeb, "Effect of age, sex and level of surgical difficulty on inflammatory complications after third molar surgery," Journal of Maxillofacial and Oral Surgery, vol. 14, no. 1, pp. 7-12, 2015.

[26] A. W. Ferrante, "Obesity-induced inflammation: a metabolic dialogue in the language of inflammation," Journal of Internal Medicine, vol. 262, no. 4, pp. 408-414, 2007.

[27] E. D. Kantor, J. W. Lampe, M. Kratz, and E. White, "Lifestyle factors and inflammation: associations by body mass index," PLoS One, vol. 8, no. 7, article e67833, 2013.

[28] O. A. Akadiri and A. E. Obiechina, "Assessment of difficulty in third molar surgery-A systematic review," Journal of Oral and Maxillofacial Surgery, vol. 67, no. 4, pp. 771-774, 2009.

[29] S. A. Bello, W. L. Adeyemo, B. O. Bamgbose, E. V. Obi, and A. A. Adeyinka, "Effect of age, impaction types and operative time on inflammatory tissue reactions following lower third molar surgery," Head and Face Medicine, vol. 7, pp. 1-8, 2011.

[30] V. Olmedo Gaya, M. Vallecillo Capilla, and R. Gálvez Mateos, "Relación de las variables del paciente y de la intervención con el dolor y la inflamación postoperatorios en la exodoncia de los terceros molares," Medicina Oral, vol. 7, pp. 360-369, 2002.

[31] F. Licastro, G. Candore, D. Lio et al., "Innate immunity and inflammation in ageing: a key for understanding age-related diseases," Immunity and Ageing, vol. 2, pp. 338-344, 2005.

[32] A. P. Field and D. B. Wright, "A primer on using multilevel models in clinical and experimental psychopathology research," Journal of Experimental Psychopathology, vol. 2, no. 2, pp. 271-293, 2011. 


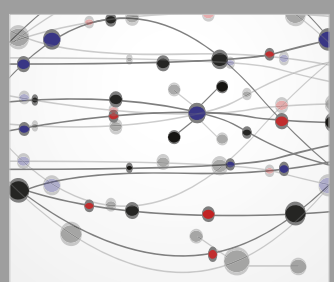

The Scientific World Journal
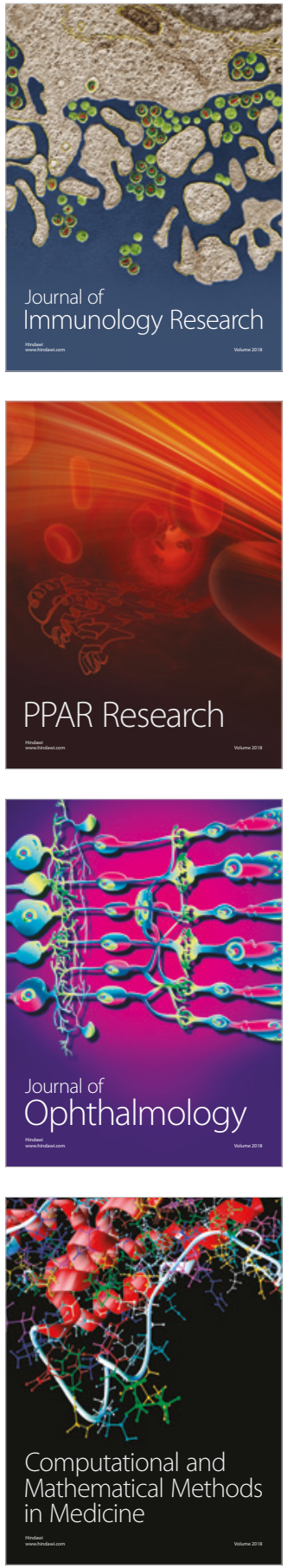

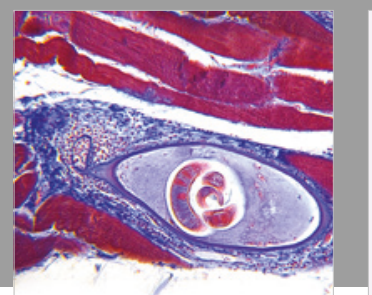

Gastroenterology Research and Practice

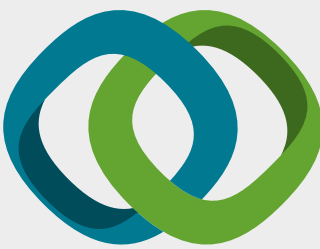

\section{Hindawi}

Submit your manuscripts at

www.hindawi.com
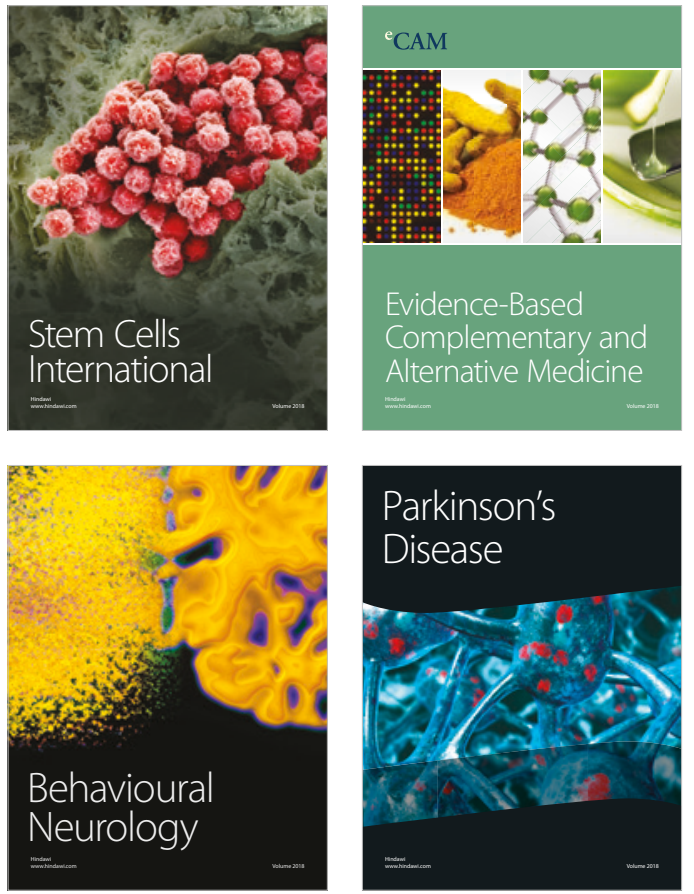

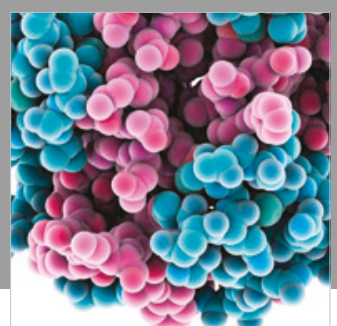

ournal of

Diabetes Research

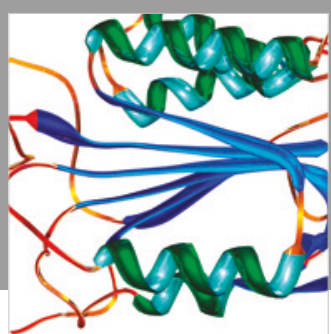

Disease Markers
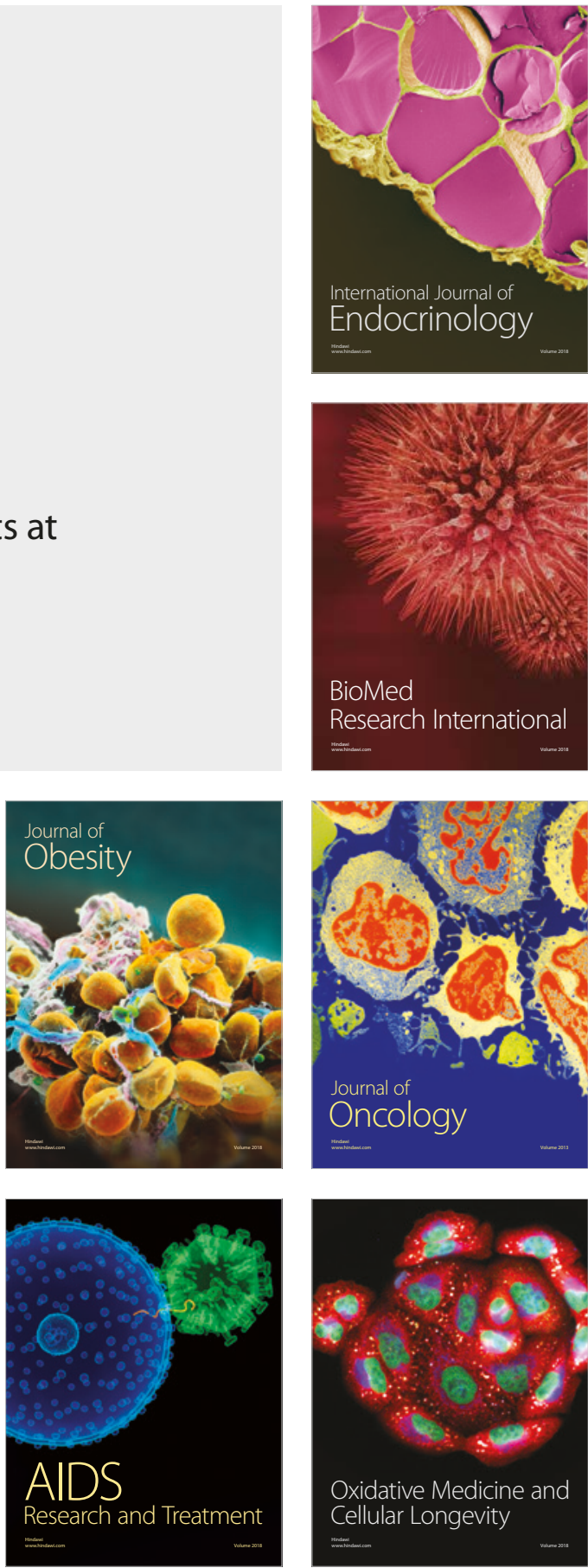